\title{
Open Access Movement: A Probable Solution of Present Crisis in Scholarly Communications
}

\author{
Subhajit Panda \\ Assistant Librarian \\ University Library, Chandigarh University \\ Mohali, Punjab (140413) \\ e-mail: subhajit.e9641@cumail.in
}

\begin{abstract}
The spirit and philosophy of Open Access are in sync with FAIFE owing to its visible role in sharing intellectual freedom for building information democracy. But with exponential increase of cost of scholarly research publication and capture of a huge portion of publication industry by for-profit publishers create a void between the research and researcher, information and seeker, educator and learner, query and the solutions. This paper illustrates the hidden cause of this crisis in scholarly communication and give a brief understanding of total open access movement, from past initiative to future plans. Additionally this paper thoroughly pointed out the tools and platforms which can be used by educators and researchers to promote this open access movement with a great success. The paper reflects the value of open access movement in the way to eliminate communication gap in terms of scholarly research work.
\end{abstract}

Keywords: BOAI, CC Licensing, CORE, EDMODO, Mason OER Metafinder, MEGA, Crisis in Scholarly Communication, OA Button, Open Access Movement, Plan S, ZENODO

\section{Introduction:}

The term serials crisis is commonly used to highlight the exponential increase in subscription cost of many scholarly journals, particularly, which are published by for-profit publishers. This crisis in academic publishing is "widely perceived", which is to do with the combined pressure of budget cuts at universities, increased costs of journals, unbearable economic recession and the global economic downturns in recent times. It creates a void between the research and the researcher. This serials crisis phenomenon led to the initiation of the global open access movement to help the researchers to come out of over-dependency on monopolistic corporate publishing companies (Das, 2015). This paper based on the general study about the crisis in terms of accessibility in scholarly research publications, its causes and try to find some actual solution with total open access movement. It taken into consideration from the beginning to the future plan and present implementation.

\section{Review of the Literature:}

Crisis of scholarly communication is neither a new term nor a new area of research. With the evaluation of new publishing policies and capturing of the maximum part of publishing market by commercial publisher creates a void between the research and researcher, information and seeker, educator and learner, query and the solutions. Academicians and researcher try to put this matter by their survey time to time and results of many open access movement which try to eliminate this digital divide nowadays. 
The first part of his paper, "The Crisis in Scholarly Communication", Corbett (2009), gave a primary understanding of how the cost of journal subscriptions causes tremendous difficulties for the researcher and educators to access the knowledge in the right time. They don't have the right to share their own works. the first in a two-part series presents an overview of the crisis in scholarly communication and discusses the groundwork that must be laid to develop successful programs to address the crisis on college and university campuses. As a solution, he recommends the involvement of R\&D institutions, libraries and de facto centres to educate the faculty about the issue and advocate for more sustainable publishing models.

Hughton (2002) emphasize the scholarly communication crisis with economical analysis by describing and scoping the system of scholarly communication in Australia and exploring the economics that governs it. The paper study the relationship between the author and the publishing model of different journal publishers, the cost and incentive structures underpinning the creation, production and distribution of scholarly content; and the underlying economics of scholarly communication within Australia. As a solution, brief analyses of some alternative publishing initiatives are included.

After reviewing the history and parameters of the scholarly publication structure, Schatzle (2006) proposed that the current state of scholarly communication requires change. The greatly increased cost of serials combined with the increase in the number of titles has resulted in a reduction in the number of serials an academic institution can reasonably purchase. Libraries have begun to address the crisis in serials pricing by removing the commercial publisher from the process entirely. Similar as of the title "A Proposed Solution to the Scholarly Communications Crisis", Schatzle employs the principles of game theory in proposing a new solution to the crisis. In this theory, he proposed the libraries to banded together in library consortia and consortia auction off their purchase budgets to various producers or sellers. It allows libraries to increase their leverage and libraries can cap spending as well as increase access to serials.

All of the previous study proposed open access publication as an ultimate solution of this crisis. However our present study pointed out the lacks of open access publications and prescribed the total open access movement as a final solution.

\section{Objectives of the Study:}

- To examine the causes of the crisis in the scholarly communication.

- To display how only open access publications can't be the ultimate solution of this crisis.

- To proposed a total open access movement to eliminate this digital divide.

- To state this open access movement from past initiative to future plans.

- To promote tools and platforms for support this open access movement which are free to use.

\section{Scope of the Study:}

The study displays a general overview of the current status of the crisis in scholarly communication and the causes which mainly responsible for this communication gap. This paper also emphasizes why only open access can't be the final solution to this crisis. And the primary aim of this paper is to aware the educators and researchers about such tools and platforms which can be used after proper evaluation and comparison for content creation, 
dissemination, preservation \& archiving and which ultimate be the present solution of this crisis in scholarly communication.

\section{Crisis in Scholarly Communication:}

The "crisis in scholarly communication" is characterized by the rising costs of providing access to scholarly publications that outpace the growth of library budgets and the increased restrictions on usage of scholarly material in the electronic environment. The overall result is reduced access to the published literature. Simultaneously, three additional developments in the commercial journal publishing world placed scholarly communication in a situation widely referred to as a "crisis":

- The high cost of academic journals,

- The consolidation of the publishing industry; especially in the sciences; and

- New journal pricing structures.

Thus it is finally the loss of access to scholarly research. Interestingly, much of the scholarly publishing system is based on a gift economy. Authors and reviewers provide their work free of charge to publishers in order to support the dissemination and exchange of scholarly research. Still, there are significant costs to publishers involved in producing, publishing, and providing access to the scholarly record. The pressures to publish come from universities themselves in the tenure and promotion requirements, but some feel the costs of scholarly publishing in the long run are unsustainable. (MSU Libraries, n.d.)

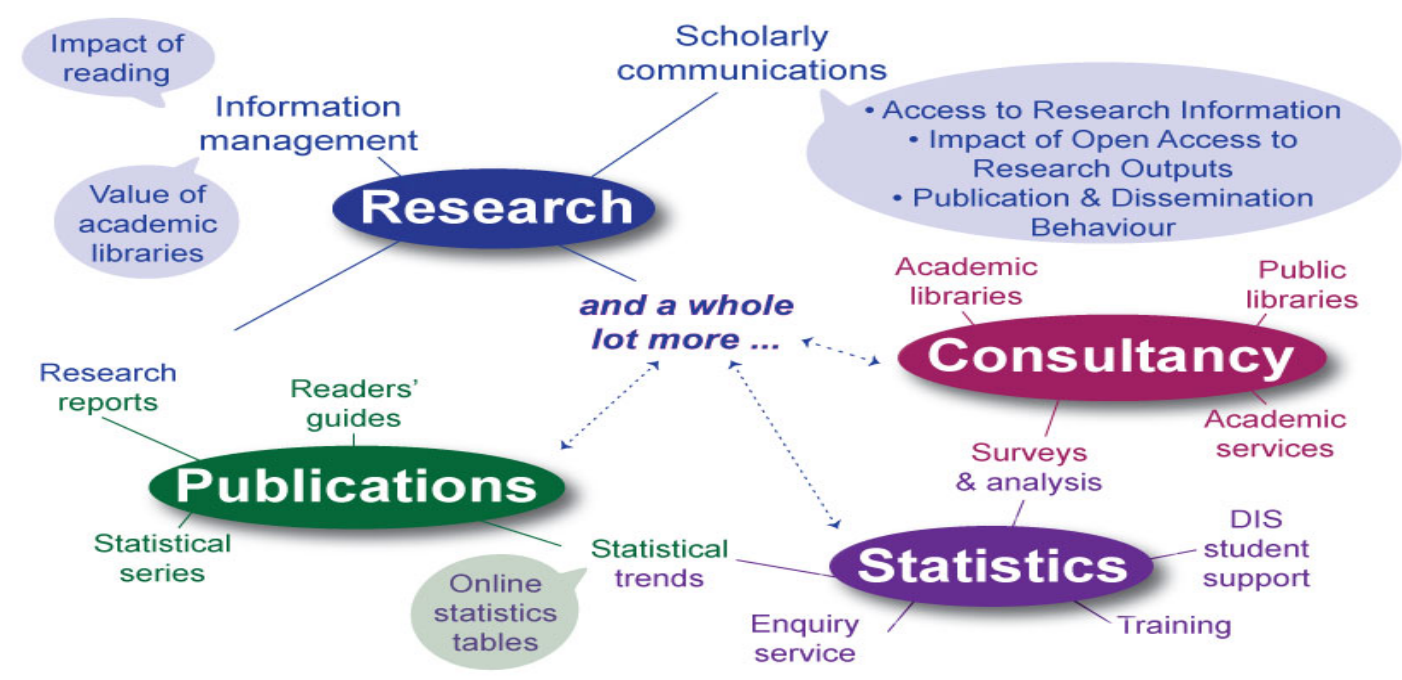

Fig 1. Scholarly Communication Circle

\section{Causes of the Problem:}

\section{a) High cost of academic journals:}

An overview of scholarly communication would not be complete without a brief review of the so-called 'serials crisis' that has taken place in scholarly libraries throughout the world over the last 40 years. The situation has been intensified over the last twenty years or so by ongoing annual price increases for journals that have exceeded inflation, sometimes by many times. E.g. It found that from 2009 to 2019 the increase in median price of journals (e.g. 
Cambridge University Press, Sage etc) from a group of twelve scholarly publishers increased between $85-194 \%$. Due to price increases, libraries are subscribing to fewer journals titles. The decrease in subscriptions has resulted in publishers charging even higher prices to maintain their revenue.

\section{b) Bundling of journal titles:}

Reacting to the criticism and to the journal cancellations, the scholarly publishing industry provided libraries new economies in the form of journal bundling. The "bundling" of dozens or even hundreds of electronic journal titles into aggregated products, instead of selling separate titles is affecting scholarly communication. It is complex pricing schemes. Librarians have dubbed such offers "The Big Deal". The publishers or aggregators do not allow libraries to cancel a single title in the bundle during the contract period (Bergman, 2006). E.g. EBSCO, Proquest, Science Direct, etc.

\section{c) Library Consortia:}

The second new economy of publishers is to grant deep discounts to library consortia. Publishers competed with each other for libraries' business. They grant deep discounts that essentially resolved the serials crisis. But they also impose some conditions on libraries. Most of Consortia include those journals which are of lower quality or irrelevant to information need of that institution. Libraries are thus forced to spend money for those titles they don't want.

\section{d) Publisher consolidation and resultant new pricing structures:}

A small number of commercial publishers control a large part of the market of scholarly publication. Commercial publishers charge more for their materials than scholarly societies or university presses. Commercial journal publishers are expanding their market control through acquisitions, mergers, and the purchase of titles from scholarly societies. Some societies had sold their journals to commercial publishers, who capitalize by significantly increasing the cost of the journal. Some examples of such journals,

- $\quad$ EBSCO acquired the H.W. Wilson Company in June of 2011.

- EBSCO purchased NetLibrary in 2010 from OCLC.

- Proquest provides online access to LISA which was publication of LA (now CILIP).

- Elsevier has merged some publishers.

- Various journals of ASLIB and CILIP are being published by Emerald.

\section{Solution: Only Open Access Publication?}

The crisis created by the publishing world developments, has led to the emergence of the open access (OA). OA essentially means free access to the users. This term is commonly associated with scholarly material. OA denotes that electronic scholarly articles are available freely at the point of use. There are two main ways of open access - self archiving and open access journal platforms. Due to open access publishing, there are various issues which have positive and negative impacts on scholarly communication, publishers, libraries, users, authors, learned societies, indexing and abstracting services, etc. OA has fully not solved this problem i.e. crisis in scholarly communication. There are various issues with OA which was as follows: 


\section{a) Author-pays:}

The Author-pays model refers to the operational model "in which publication charges are paid by the author, the author's institution or research program" (Wellcome Trust, 2004). BioMed Central (BMC), an OA publisher, uses the Author-pays model. The charge for an article is in the range of $\$ 570-\$ 1645$ depending on which journal you choose to submit. PLoS charge a fee of $\$ 1250$ - $\$ 2750$. The proponent for author-pays model argues the author-pays can help achieve economic efficiency (Wellcome Trust, 2004).

\section{b) Commercial Publishers:}

Scholarly publishing is going through transitional phase because of open access. Publishers are facing major problems from open access movement. Initially several journal publishers resisted the transition to open access. It is clear that open access will harm the ways of doing business of commercial publishers in general and their profits in particular. Some publishers offer option to authors for open access publication (hybrid method) and are trying to evolve strategies to safeguard their interest in this age of open access movement. The authors who wish to make their articles immediately openly accessible have to pay a fee for this option. However with time now some of the publishers support OA medium of publications, e.g. Royal Society of Chemistry, Taylor \& Francis, Elsevier, Oxford University Press, Blackwell etc.

\section{c) Predatory Publishers:}

Predatory publishers are poisoning gold OA, and they threaten to harm all of scholarly communication. The gold OA model is failing, and the valuable validation feature that the traditional publishing model provided is being lost. This corruption of scholarly publishing is making the future of all scholarly communication doubtful. Many in developing countries have discovered scholarly publishing as an easy way to make money, and it has the benefit of low startup costs. The fatal flaw of the gold OA model is the built-in conflict of interest: the more papers a journal accepts, the more money it makes. There is no way around this conflict, and it is this that has created the whole problem of predatory publishers (Beall, 2013).

\section{d) Quality of Information:}

There are millions of researchers around the world desperate to publish with predatory publishers, and these publishers are eager to have them as customers. Gold OA author pay models may possibly reduce the quality of journals. Editorial procedure of these journals is doubtful and is not rigorous upto mark. Further the use of print journals is decreasing. Users prefer to access online journal even if it has print counterpart (Groote \& Dorsch, 2001). The convenience is major factor for selecting articles from OA /free journal on the web. They prefer the articles which are easily available on the web over the quality one. Users tended to limiting their choices to what was easily available. Thus users are sacrificing qualitative information at the cost of convenience. In some cases, whatever is freely available on the Web is being used most often. Various citation analysis studies have shown that OA papers are being used by academicians (Kumar and Bansal, 2008). Information seekers readily sacrifice content for convenience (Connaway, Dickey, \& Radford, 2011). If open access publishing or repositories become the norm, then many reputed journals would disappear. Thus OA has an adverse impact on quality control of scholarly commutation (Beall, 2013). 


\section{e) Information Overload:}

One result of this OA has been the publication of millions of useless articles that create a lot of academic noise. It creates information overload. The excessive number of scholarly articles being published makes searching more difficult, and it makes keeping up with one's field more difficult.

\section{f) Learned Societies and Associations:}

The societies and associations play a vital role in disseminating research information through the scholarly journals they sponsor. Society journals are among the best in the world. The studies have shown that in the physical sciences alone, $46 \%$ of articles are published by societies, but they attract more $52 \%$ of all the citations (Velterop, 2005). The principal benefit of joining membership of scholarly societies and associations has been 'free' or discounted subscription to their journals. When societies adopt open access publishing, the subscription model of membership will not have much of a future. Now a question arises how these societies will compensate the loss of revenues that comes from open access publishing. Thus open access is affecting the role of societies and associations.

\section{Probable Solution: Total Open Access Movement}

The one and probably only solution of this problem is not just open access but a total open access movement in every aspect of scholarly publication. As per the theme of the present study the Drury's Principle (Francis Keese Wynkoop Drury, 1930) may be rewritten as "to provide the right content, to the right user, at right time". And to do so there are some initiatives (e.g. Budapest Open Access Initiatives), some licenses (e.g. Creative Common Licenses), some plans (e.g. Plan S or cOAlition S) and to implement this there are some open access tools after evaluation and comparison which can use by learners and educators for creation, dissemination and preservation of scholarly content in digital media.

\section{The Beginning:}

As stated in the original declaration of Budapest Open Access Initiative, open access is literature "freely availability on the public internet, permitting any users to read, download, copy, distribute, print, search, or link to the full texts of these articles, crawl them for indexing, pass them as data to software, or use them for any other lawful purpose, without financial, legal, or technical barriers other than those inseparable from gaining access to the internet itself. The only constraint on reproduction and distribution, and the only role for copyright in this domain, should be to give authors control over the integrity of their work and the right to be properly acknowledged and cited" (BOAI, 2002).

\section{Future Initiatives:}

Before we start with the cutting-edge OA discovery tools, it is pertinent to discuss an initiative, launched in September 2018, called Plan S (Plan S, 2018). "cOAlition S", an international consortium of research funders, supports the Plan S.Plan S envisages that publicly funded research findings must be published in compliant OA journals/platforms w.e.f. 2021. Distinctive features of this plan are enumerated below: 
- Authors or their institutions hold the copyright of their publications and the publications must be licensed under CC-BY open license. (Attribution) in accordance with theBerlin Declaration;

- Quality OA Journals/Platforms/Repositories must support the Funders must create rigorous service standards and specifications;

- Well coordinated incentives shall be provided by the funders in cases wherein such system does not exist for its development and maintenance. Such incentives shall also include funding for establishing necessary OA infrastructure;

- Funders or research institutions must be covered the open access publishing fees, where applicable, not by the researchers. It is also recognized that all researchers should be able to publish their Open Access work;

- Funders must support the various OA business models and the OA fees (with payment capping) must be transparent and justifiable through various qualitative measures standardization reflected in their services.

- The Funders encourage governments, universities, research organisations, libraries, academies, and learned societies to align their strategies, policies, and practices, notably to ensure transparency.

- The Plan-S principles shall be applicable to all types of scholarly publications, but with longer and flexible timeline in case of monographs and book chapters to attain OAAS they require separate and due process;

- During the transition period, the funders may financially contribute and support the 'hybrid' model of publishing through on adhoc basis.

- Monitoring of adherence and compliance to Plan-S principles will be undertaken by the various funding bodies and sanctions nay be levied in cases of non-compliant beneficiaries/grantees.

- Funding decisions will depend on the value and intrinsic merit of the work only and not on other factors including publication channel, its impact factor (or other journal metrics), or the publisher. (Plan S, n.d.)

- "Plan $S$ " is definitely going to have an impact on the whole OA ecosystem and implications on how the OA content is being delivered to the last man in the queue while reaching the last mile.

\section{Present Implementation: OA Tools and Platforms}

\section{a) Multimedia Content Creation:}

(i) Screen Sharing Tools: Screen sharing is an easy yet powerful way to foster immediate collaboration, anywhere at any time. Users can to share a live video feed of what is happening on their computer's screen, with other participants of the web conference. E.g. Screenleap and Dead Simple Screen Sharing are two of the most popular and widely used screen sharing platforms.

(ii) Screen Recording Tools: Screen recording is a way of sharing a captured screen or video, recording in window or full screen modes, sharing video instructions all while allowing users to visually see the information in the same way as the sharer. It helps educator in the process of flipped learning, blended learning and online learning and for student to improve their self study and they become more proactive by $24 / 7$ online access to knowledge. E.g. LOOM, Free Cam and FlashBack Express 
b) Multimedia Licensing: Creative Common Licensing (CC Licensing):

Open Access Licenses are free legal tool provides by Creative Commons (CC), a global nonprofit organization that enables sharing and reuse of creativity and knowledge. CC licenses restrained the strictness of Copyright from "All Rights Reserved" to "Some Rights Reserved", i.e., offer creators a spectrum of choices between retaining all rights and relinquishing all rights (public domain). This spectrum of choices evolves six basic category of CC licenses (Creative Commons, 2017), viz,

Table 1. Creative Commons (CC) Licenses

\begin{tabular}{|c|c|c|c|c|c|}
\hline CC License & $\begin{array}{l}\text { Copy \& } \\
\text { Publish }\end{array}$ & $\begin{array}{c}\text { Attribution } \\
\text { Required }\end{array}$ & $\begin{array}{c}\text { Commercial } \\
\text { Use }\end{array}$ & $\begin{array}{c}\text { Modify \& } \\
\text { Adapt }\end{array}$ & $\begin{array}{l}\text { Change } \\
\text { License }\end{array}$ \\
\hline PDM(Public Domain) & $\checkmark$ & $\mathrm{x}$ & $\checkmark$ & $\checkmark$ & $\checkmark$ \\
\hline CC BY (Attribute) & $\checkmark$ & $\checkmark$ & $\checkmark$ & $\checkmark$ & $\checkmark$ \\
\hline $\begin{array}{l}\text { CC BY-SA } \\
\text { (Attribution-ShareAlike) }\end{array}$ & $\checkmark$ & $\checkmark$ & $\checkmark$ & $\checkmark$ & $\mathrm{x}$ \\
\hline $\begin{array}{l}C C B Y-N D \\
\text { (Attribution-NoDerivs) }\end{array}$ & $\checkmark$ & $\checkmark$ & $\checkmark$ & $\mathrm{x}$ & $\checkmark$ \\
\hline $\begin{array}{l}\text { CC BY-NC } \\
\text { (Attribution- } \\
\text { NonCommercial) }\end{array}$ & $\checkmark$ & $\checkmark$ & $\mathrm{x}$ & $\checkmark$ & $\checkmark$ \\
\hline $\begin{array}{l}C C B Y-N C-S A \\
\text { (Attribution- } \\
\text { NonCommercial- } \\
\text { ShareAlike) } \\
\end{array}$ & $\checkmark$ & $\checkmark$ & $\mathrm{x}$ & $\checkmark$ & $\mathrm{x}$ \\
\hline $\begin{array}{l}C C B Y-N C-N D \\
\text { (Attribution- } \\
\text { NonCommercial- } \\
\text { NoDerivs) }\end{array}$ & $\checkmark$ & $\checkmark$ & $\mathrm{x}$ & $\mathrm{x}$ & $\checkmark$ \\
\hline
\end{tabular}

\section{c) OER Search Engine: (Mason OER Metafinder (MOM)}

The Mason OER Metafinder (MOM) helps user find Open Educational Resources. Unlike other OER discovery sites (e.g, OER Commons, OASIS, MERLOT, OpenStax, etc.) with this Metafinder users aren't searching a static database, instead, the OER Metafinder launches a real-time, simultaneous search across 21 different sources of open educational materials as anyone hit the Search button. Because it is a real-time, federated search, it can take a bit longer than searches of pre-indexed, curated content; however, as compensation the results returned are absolutely up-to-the-minute for each search target. Additional results will continue to trickle in as the search continues running and user begin examining the results (Mason Publishing Group, n.d.).

\section{d) Web-Conferencing Solution: Free Conference Call (FCC)}

FCC offers free conference calling and video conferencing with the easiest way to stay connected with colleagues and business partners from all around the world. FCC offers global conferencing that is flexible, straightforward and secure. No reservations required and available 24/7. There are no hidden charges. FCC meets or exceeds industry security standards, including data encryption and firewalls to protect stored data. FCC allows to host high-definition audio conferences with up to 1,000 participants using domestic or local incountry dial-in numbers or VoIP (FreeConferenceCall, n.d.). 


\begin{tabular}{|c|c|c|c|}
\hline \multicolumn{5}{|c|}{ Table 2. Features of FCC } \\
\hline $\begin{array}{c}\text { Conference } \\
\text { Calls }\end{array}$ & $\begin{array}{c}\text { Video Conferencing \& Screen } \\
\text { Sharing }\end{array}$ & Meeting Wall & $\begin{array}{c}\text { Additional Free } \\
\text { Features }\end{array}$ \\
\hline Recording & Video Conferencing & Broadcaster & 1,000 Participants \\
\hline $\begin{array}{c}\text { Breakout } \\
\text { Rooms }\end{array}$ & Screen Sharing & $\begin{array}{c}\text { Meeting } \\
\text { Resources }\end{array}$ & Call Detail Reports \\
\hline Call Control & Recording and Playback & Web Controls & Mobile App \\
\hline $\begin{array}{c}\text { Meeting } \\
\text { Settings }\end{array}$ & Drawing Tools & Chat & Integrations \\
\hline VoIP & Remote Desktop & Radio & Calendar \\
\hline- & Chat & - & History \& Recordings \\
\hline- & Studio Presentation & - & - \\
\hline
\end{tabular}

Comparative study between the features of the web-conferencing tool FCC vis-a-vis other paid tools in the light of the 5A's of access, i.e. Availability, Adequacy, Accessibility, Affordability and Appropriateness; the other tools used for comparison include GotoMeeting (GTM), Zoom, Cisco Webex, Join.me etc results that FCC is affordable and stand alone tool for web-conferencing and online learning.

\section{e) e-Learning Management (eLMS) System: EDMODO}

Edmodo is a social learning platform for students, teachers, districts, and schools. It was founded in Chicago, Illinois, and was created to usher education into the 21 st century. It has become one of the leading K-12 social learning networks in the world, dedicated to linking all students with the instructions and professionals they need to reach their full potential. In addition to modernizing the way educators interact with students, Edmodo also allows them to engage students throughout each class. Using this platform, educators will get access to all the tools they need to give the students a more exciting learning experience (Edmodo, 2005).

\begin{tabular}{|l|l|}
\hline \multicolumn{2}{|c|}{ Table 3. Overview of Edmodo Features } \\
\hline Accelerate learning goals & Send an Assignment \\
\hline Activate your free admin account & Send a Quiz \\
\hline Award badges to individual students & Create a Small Group \\
\hline Build a network of communities & Add Content to Your Library \\
\hline Create polls for students & Send and View Your Direct Messages \\
\hline Measure student progress & $\begin{array}{l}\text { Moderate Student Posts \& Read Only } \\
\text { Status }\end{array}$ \\
\hline $\begin{array}{l}\text { Network that connects students, } \\
\text { administrators, parents }\end{array}$ & Manage and Remove Group Members \\
\hline Online classroom discussions & Connect Parents to your Students \\
\hline Personalize with apps & \\
\hline
\end{tabular}

\section{f) Multimedia Content Preservation: Cloud Storage (MEGA)}

There are several popular cloud storage services available including Google Drive, DropBox, OneDrive, etc. But as witnessed in the recent times, the requirement of cloud storage space has escalated, users want to explore cloud platforms with higher storage capabilities. MEGA is one such service which justifies the user needs comprehensively. MEGA's core is end-toend encrypted cloud storage and communication. In the future, MEGA will continue to develop innovative products and features that complement its existing platform for both individuals and businesses to help them improve their security on the Internet without 
compromising on usability. MEGA has $186 \mathrm{M}+$ registered users (with $10 \mathrm{M}+$ daily active users), 77B+files uploaded and 200+countries have users on MEGA (MEGA, n.d.). It is available in both Desktop and Mobile App version.

\section{g) Multimedia Dissemination Tool:}

(i) CORE: It has free and seamless access of millions of research papers around the world, because the main aim of core is to believe that knowledge should be used for public good and find how the knowledge can be distributed in a better way. Core collects millions of research papers from around the world and offer them free for everyone. Core has world's largest collection of OA full text which used by researchers, libraries, s/w developers, funder and many more. Our aggregated content come from thousands of institutional and subject repositories as well as journals and covers all research disciplines. We aim to support the right of citizen to access free of charge research to which they contributing by paying taxes. Provides support both content consumers and content providers by working collaboratively with them. Contribute to cultural change by promoting OA, the first growing movement for good. Make use of artificial intelligence and machine learning techniques to enrich and organize research contents support usage and discover of knowledge of their interest (CORE, n.d.).

(ii) Open Access Button: Students, researchers and academics require fairness and transparency in scholarly communications and all its aspect like ownership, creation and readership. OA Button (OAB) launched in November 2013, envisages to facilitate such system by establishing a library-centric, open-sources, and non-commercial mechanism to avoid hitting paywalls. OA Button includes all of the world's aggregated repositories, hybrid articles, open access journals and those on authors' pages as the source of data, e.g. Unpaywall Data, Share, CORE, OpenAIRE, Dissem.in, Europe PMC \& BASE (Open Access Button, n.d.).

(iii) Zenodo: OpenAIRE is an acronym for "Open Access Infrastructure for Research in Europe". OpenAIRE helps Horizon 2020 researchers report their publications to the EC Participant Portal and comply with the European Commission Open Access Policy and Research Data Pilot.OpenAIRE does this by aggregating European funded research output from nearly 1000 repositories from all over the world and makes them available via the OpenAIRE portal.Zenodo (https://zenodo.org) is part of OpenAIRE. Zenodo, launched in 2013, is a multi-disciplinary open repository maintained by CERN. Datasets, documents and other research materials can be located via the Zenodo search engine.Scholars from any research discipline can upload data in any file format. A digital object identifier (DOI) is automatically assigned to all Zenodo files. The name "Zenodo" is derived from "Zenodotus", the first librarian of the Ancient Library of Alexandria and father of the first recorded use of metadata, a landmark in library history (Zenodo, 2013).All of the Zenodo Data is stored in CERN Data Center. CERN has considerable knowledge and experience in building and operating large scale digital repositories and a commitment to maintain this data centre to collect and store 100s of PBs of LHC data as it grows over the next 20 years (GRASS Wiki, 2019).

\section{Conclusions:}

These pricing practices and use restrictions have eroded scholarly communication by leaving libraries unable to keep pace with the increasing amount and costs of scholarly materials and 
prohibiting scholars from freely sharing their research. It became clear to all involved that a major paradigm-shift and monumental publishing market corrections were needed. At present scholarly communication is in a mess. The gold OA model is demonstrating many significant weaknesses and drawbacks, so academicians, librarians and others need to re-examine the model with a healthy skepticism instead of doubling down and promoting it as the final solution. Thus only open access publications are not the actual solution of the crisis, and we have to develop a total open access movement from content creation, to content publication, dissemination, preservation, and archiving. The tools and platforms acknowledged for this motive are either cost-free or the basic version is free, or it offers educators \& learners some extended free versions. This is right time to think in a long way otherwise scholarly publication would face much more trouble in the coming year.

\section{References:}

1. Beall, J. (2013). Predatory publishing is just one of the consequences of gold open access. Learned Publishing, 26(2), 79-83. https://doi.org/10.1087/20130203

2. Bergman, S. S. (2006). The scholarly communication movement: highlights and recent developments. Collection Building, 25(4), 108-128. https://doi.org/10.1108/01604950610705989

3. BOAI. (2002, February 14). Budapest Open Access Initiative | Read the Budapest Open Access Initiative. Retrieved July 10, 2020, from http://www.budapestopenaccessinitiative.org/read

4. Connaway, L. S., Dickey, T. J., \& Radford, M. L. (2011). "If it is too inconvenient I'm not going after it:" Convenience as a critical factor in information-seeking behaviors. Library \& Information Science Research, 33(3), 179-190. https://doi.org/10.1016/j.lisr.2010.12.002

5. Corbett, H. (2009, March 9). The Crisis in Scholarly Communication, Part I: Understanding the Issues and Engaging Your Faculty. Technical Services Quarterly, 26(2), 125-134. https://doi.org/10.1080/07317130802268522

6. CORE. (n.d.). About CORE. Retrieved July 11, 2020, from https://core.ac.uk/about/

7. Creative Commons. (2017, November 7). About The Licenses - Creative Commons. Retrieved July 10, 2020, from https://creativecommons.org/licenses/

8. Das, A. K. (2015). Module 1 Scholarly Communication | Unit 1-4. Retrieved July 9, 2020, from http://unesdoc.unesco.org/images/0023/002319/231938e.pdf

9. Edmodo. (2005). Edmodo: The World's Largest Learning Community. Retrieved July 11, 2020, from https://www.edmodo.com/

10. FreeConferenceCall. (n.d.). Features | FreeConferenceCall.com. Retrieved July 10, 2020, from https://www.freeconferencecall.com/global/in/features

11. Groote, S. L. D., \& Dorsch, J. L. (2001). Online journals: impact on print journal usage. Bulletin of the Medical Library Association, 89(4), 372-378. Retrieved July 12, 2020, from https://pubmed.ncbi.nlm.nih.gov/11837259/

12. GRASS Wiki. (2019, July 11). GitHub-Zenodo linkage. Retrieved July 11, 2020, from grasswiki.osgeo.org website: https://grasswiki.osgeo.org/wiki/GitHubZenodo_linkage

13. Houghton, J. (2002). The Crisis in Scholarly Communication: an Economic Analysis Background and Context. Retrieved July 10, 2020, from https://www.vala.org.au/vala2002/2002pdf/16Houton.pdf

14. Kumar, S. and Bansal, J. (2008, June 1). The impact of Open Access on scholarly communication and its future. Library Herald, 46(2), 91-102. Retrieved July 12, 2020, from http://eprints.rclis.org/16856/ 
15. Mason Publishing Group. (n.d.). About the Mason OER Metafinder (MOM) - Mason Publishing Group. Retrieved July 10, 2020, from https://publishing.gmu.edu/whosusing-the-mason-oer-metafinder/

16. MEGA. (n.d.). About MEGA - The Privacy Company. Retrieved July 11, 2020, from https://mega.nz/about/main

17. MSU Libraries. (n.d.). Crisis in Scholarly Communications | Scholarly Communication | Collections | MSU Libraries. Retrieved July 12, 2020, from https://lib.msu.edu/about/collections/scholcomm/more/\#: :text=The\%20\%22crisis\%2 0in\%20scholarly\%20communication

18. Open Access Button. (n.d.). Open Access Button. Retrieved July 11, 2020, from https://openaccessbutton.org/about

19. Plan S. (2018). About | Plan S. Retrieved July 10, 2020, from https://www.coalitions.org/about/

20. Plan S. (n.d.). Principles and Implementation | Plan S. Retrieved July 10, 2020, from https://www.coalition-s.org/addendum-to-the-coalition-s-guidance-on-theimplementation-of-plan-s/principles-and-implementation/

21. Schatzle, C. (2006). A Proposed Solution to the Scholarly Communications Crisis. Journal of Access Services, 3(3), 37-47. https://doi.org/10.1300/j204v03n03_04

22. Velterop, J. (Jan) J. (2005). Open Access Publishing And Scholarly Societies A Guide. $\quad$ Retrieved July 12, 2020, from https://www.budapestopenaccessinitiative.org/pdf/open_access_publishing_and_schol arly_societies.pdf

23. Wellcome Trust. (2004) Cost and business models in scientific research publishing. Retrieved on July 12, 2020 from http://www.wellcome.ac.uk/assets/wtd003184.pdf. 